\title{
Correction of: Using New and Emerging Technologies to Identify and Respond to Suicidality Among Help-Seeking Young People: A Cross-Sectional Study
}

Frank Iorfino, BSc (Psych), MBMSc; Tracey A Davenport, BA (Hons), eMBA; Laura Ospina-Pinillos, MD; Daniel F Hermens, PhD; Shane Cross, BPsy (Hons), MPsych(Clinical), PhD; Jane Burns, PhD; Ian B Hickie, AM, MD, FRANZCP, FASSA

Brain and Mind Centre, The University of Sydney, Sydney, Australia

Corresponding Author:

Frank Iorfino, BSc (Psych), MBMSc

Brain and Mind Centre

The University of Sydney

94 Mallett St, Camperdown

Sydney, 2050

Australia

Phone: 610293510827

Email: frank.iorfino@sydney.edu.au

\section{Related Article:}

Correction of: http://www.jmir.org/2017/7/e247/

(J Med Internet Res 2017;19(10):e310) doi: 10.2196/jmir.8804

In the paper by Frank Iorfino et al, "Using New and Emerging Technologies to Identify and Respond to Suicidality Among Help-Seeking Young People: A Cross-Sectional Study" (J Med Internet Res 2017;19(7):e247), a mistake was made in the final stage of copy editing. In the Introduction, the first sentence of the second paragraph should have appeared as follows: "This is a particularly pertinent issue given that almost half of those who have died by suicide had contact with a primary care provider within one month of the suicide [12], and one-quarter of those with depression who die by suicide are likely to have been in active engagement with mental health services at the time of death [13-16]."

Instead of the above, the first part of the sentence was incorrectly worded as: "This is a particularly pertinent issue given that almost half of those who have died by suicide had contact with a primary care provider within one month before committing suicide [12]..." (emphasis added). The phrase "committing suicide" was chosen by the proofreader without realizing that it can be perceived as stigmatizing and at times offensive in the mental health field. We regret this error and have updated our copyediting guidelines to reflect the recommended terminology [1].

Another minor error was introduced in the section, "Suicidality Escalation in Primary Care-A Proof of Concept." In the first paragraph, where factors reported by clinicians as influencing the decision to escalate an individual are given, the "(4)" was repeated. The list should have appeared as follows: (1) concerns over specific suicidal ideation attributes such as little of control over suicidal thoughts (5/7 participants) and closeness to making an attempt (5/7 participants), (2) concerns over the presence of hypomania or psychosis-like symptoms (1/7 participants), (3) recent plans to make an attempt that were identified upon follow-up (1/7 participants), (4) few protective factors identified upon follow-up (1/7 participants), (5) few protective factors identified at follow-up (1/7 participants), and (6) recent self-harm (1/7 participants).

The corrected article will appear in the online version of the paper on the JMIR website on October 30, 2017, together with the publication of this correction notice. Because this was made after submission to PubMed Central, the corrected article will also be re-submitted to PubMed Central.

\section{Reference}

1. Mindframe. Mindframe National Media Initiative. Canberra: Australian Government, Department of Health; 2014. Reporting and portrayal of suicide URL: http://www.mindframe-media.info/for-media/reporting-suicide 
Edited by G Eysenbach; this is a non-peer-reviewed article. Submitted 21.08.17; accepted 22.08.17; published 30.10.17.

Please cite as:

Iorfino F, Davenport TA, Ospina-Pinillos L, Hermens DF, Cross S, Burns J, Hickie IB

Correction of: Using New and Emerging Technologies to Identify and Respond to Suicidality Among Help-Seeking Young People: A Cross-Sectional Study

J Med Internet Res 2017;19(10):e310

URL: http://www.jmir.org/2017/10/e310/

doi: $10.2196 /$ jmir.8804

PMID: $\underline{30578183}$

CFrank Iorfino, Tracey A Davenport, Laura Ospina-Pinillos, Daniel F Hermens, Shane Cross, Jane Burns, Ian B Hickie. Originally published in the Journal of Medical Internet Research (http://www.jmir.org), 30.10.2017. This is an open-access article distributed under the terms of the Creative Commons Attribution License (https://creativecommons.org/licenses/by/4.0/), which permits unrestricted use, distribution, and reproduction in any medium, provided the original work, first published in the Journal of Medical Internet Research, is properly cited. The complete bibliographic information, a link to the original publication on http://www.jmir.org/, as well as this copyright and license information must be included. 